\title{
Combined photocatalytic and Fenton oxidation for oily wastewater treatment
}

\author{
Yasmina Mokhbi ${ }^{1} \cdot$ Mourad Korichi $^{1} \cdot$ Zineb Akchiche $^{1}$
}

Received: 26 December 2017 / Accepted: 19 February 2019 / Published online: 5 March 2019

(c) The Author(s) 2019

\begin{abstract}
Our studies focused on assessing the effectiveness of the heterogeneous photocatalysis method $\left(\mathrm{TiO}_{2} / \mathrm{UV}\right)$ and examining the feasibility of photocatalysis coupling with hydrogen peroxide in the treatment of oily industrial wastewater. Our oily water sample was taken from the de-oiling Haoud Berkaoui station entering, which is located $770 \mathrm{~km}$ in southern of Algiers); the AOPs investigated are $\mathrm{TiO}_{2} / \mathrm{UV}$ (photocatalysis) and $\mathrm{TiO}_{2} / \mathrm{UV} / \mathrm{Fe}^{2+} / \mathrm{H}_{2} \mathrm{O}_{2}$ (photocatalysis-Fenton's reagent). This method is used as an alternative or in addition to the conventional treatment techniques (coagulation-flocculation-decantation and filtration...etc). In this work, first we copulated between the two photocatalytic methods $\left(\mathrm{TiO}_{2} / \mathrm{UV}\right)$ and the Fenton's reagent $\left(\mathrm{H}_{2} \mathrm{O}_{2} / \mathrm{Fe}^{+2}\right)$ and then we studied the effect of various experimental factors on the treatment process: $\mathrm{pH}$, initial concentration for each of the $\mathrm{TiO}_{2}, \mathrm{H}_{2} \mathrm{O}_{2}, \mathrm{Fe}^{2+}$, and oil pollutants and finally temperature. The study showed a marked improvement in efficiency on the treated water quality in terms of color, turbidity, and COD under optimized conditions (oil concentration, quantity of catalysts, temperature, Fenton's reagent concentration, and the $\mathrm{pH}$ of the solution).
\end{abstract}

Keywords UV irradiation $\cdot$ Fenton's reagent $\cdot$ Pollutant $\cdot$ Photocatalysis $\cdot \mathrm{TiO}_{2} \cdot \mathrm{COD} \cdot$ Advanced oxidation process

\section{List of symbols}

UV Ultraviolet

$\mathrm{TiO}_{2} \quad$ Titanium dioxide

COD Chemical oxygen demand

AOPs Advanced oxidation process

$\mathrm{Re} \%$ Oil removal rate

$\mathrm{pH}_{\mathrm{PZC}} \quad \mathrm{pH}$ at the surface of a solid at zero charging

\section{Introduction}

Recently, the search for alternative methods for the treatment of oily wastewater has led to discover new technologies. Among these technologies, the so-called advanced oxidation processes (AOPs) are booming. This technology is based on the production of non-selective reactive oxidative species that will enable the oxidation of a large number of organic pollutants (Glaze et al. 1987; Bauer and Fallmann 1997). The oxidant most commonly used is the hydroxyl radical due

Yasmina Mokhbi

mokhbi26@gmail.com

1 Fac. des Sciences Appliquées, Lab. Dynamique, Interactions et Réactivité des Systèmes, Univ. Ouargla, BP 511, Ouargla, Algeria to its high reactivity $\left(E^{\circ}=2.73 \mathrm{~V}\right)$. Figure 1 shows details of all the processes, in which the AOPs are divided into two major methods: homogenous and heterogeneous, containing several techniques:

1. Chemical oxidation processes $\left(\mathrm{H}_{2} \mathrm{O}_{2} / \mathrm{Fe}^{2+}\right.$ and $\left.\mathrm{H}_{2} \mathrm{O}_{2} / \mathrm{O}_{3}\right)$ (Klavarioti et al. 2009);

2. Photocatalytic processes $\left(\mathrm{H}_{2} \mathrm{O}_{2} / \mathrm{UV}, \mathrm{O}_{3} / \mathrm{UV}\right)\left(\mathrm{Fe}^{2+} /\right.$ $\mathrm{H}_{2} \mathrm{O}_{2} / \mathrm{UV}$ and $\mathrm{TiO}_{2} / \mathrm{UV}$ );

3. Sonochemical oxidation processes;

4. Electrochemical oxidation processes (Klavarioti et al. 2009).

Among these techniques, heterogeneous photocatalysis, particularly titanium dioxide, proved to be an effective mean for the removal of pollutants present in water. This technique relies on the excitement of a semiconductor $\left(\mathrm{TiO}_{2}\right)$ by a UV light source in the aqueous phase.

Photocatalytic applications for water pollution have already reached the stage of industrial pilot. These studies have shown the efficiency of the process on families of very different organic compounds such as dyes (Guillard et al. 2003), pesticides (Hermann et al. 2000), and saturated or unsaturated hydrocarbons (Herrmann et al.1999) and phenols (Sun et al. 2009). Also recently, Wang et al. (2009) 


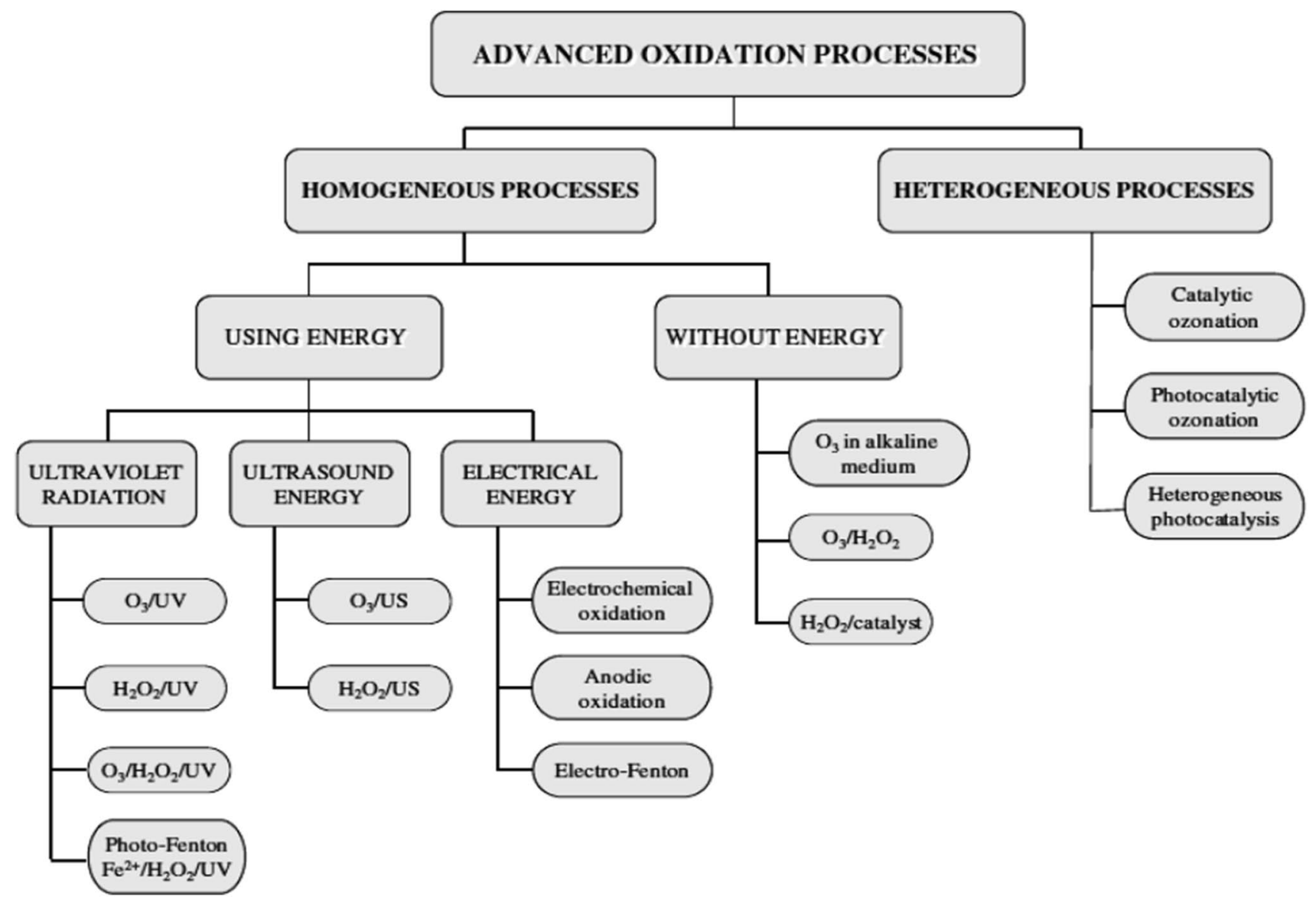

Fig. 1 Classification of advanced oxidation processes

obtained a degradation of 4-chlorophenol by photocatalysis with a nano-titanium dioxide catalyst. In the aqueous solution, photocatalytic degradations of more than 360 organic compounds have been studied (Huchon 2006). Today $\mathrm{TiO}_{2}$ is the most used semiconductor in photocatalysis.

In the other hand, Fenton's reagent method also has a very positive influence on treatment process especially for non-degradable organic pollutants.

Fenton's reagent also removes or degrades a wide variety of contaminants in aqueous solution either alone such as

- Textile industries (Arslan and Teksoy 2007; Liu et al. 2007), pharmaceutical (as a pre-treatment) (San Sebastián Martínez et al. 2003), dyeing (Gulkaya et al. 2006), dyes (Wang 2008), olive oil mills (Rivas et al. 2001; Beltrán-Heredia et al. 2001), oil (Gao et al. 2004), and cosmetics (Bautista et al. 2007);

- Reduction of polynuclear aromatic hydrocarbons (Beltrán et al. 1998) and treatment of brines (Rivas et al. 2003);

- The degradation of phenol and biphenols (Carriazo et al. 2005; Ioan et al. 2007);
- Oxidation of plastic additives industry wastewater, rubber (Flotron 2004);

Or in combination with other processes such as

- Coagulation/Fenton's reagent: for the treatment of effluent from the herbicide production industry (Martins et al. 2005) and for the treatment of landfill leachates (Martins et al. 2005; Rivas et al. 2004);

- Treatment of wastewater containing pesticides for biological treatment combined with coagulation (Chen et al. 2007).

However, the utilization of the AOPs requires certain range for what is known as COD (chemical oxygen demand) (Umar et al. 2010). It means that only wastes with relatively small COD contents $\left(\leq 5 \mathrm{~g} \mathrm{l}^{-1}\right)$ can be suitably treated by means of these processes, and if COD value was out of range, then other methods would be much more suitable for the treatment process as shown in (Fig. 2). Due to the large costly reactants that are required for the process in case of 
Incineration

\section{Wet oxidation}

\section{AOP}
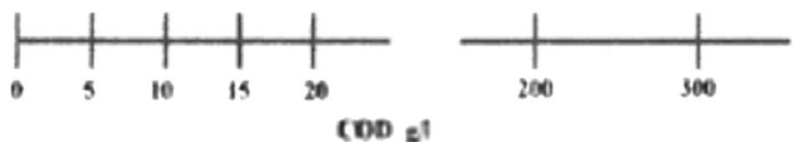

Fig. 2 Different technologies for the treatment of wastewater according to the chemical oxygen demand COD

high COD value, it would be more appropriate to use wet oxidation or incineration methods (Andreozzi et al. 1999).

Various experiments have shown that the value of COD in oily wastewater does not exceed $5 \mathrm{~g}$ per 1 liter, so the advanced oxidation process is best option to treat this kind of water.

The maximum allowed COD value for the national discharge standard is $\left(100 \mathrm{mg} \mathrm{l}^{-1}\right)$ which is difficult to achieve with the conventional physical-chemical treatment methods. Therefore, it often becomes a difficult problem for oil field that produces oily water.

\section{Objective}

The objective of this work is to study the effectiveness of photocatalysis with Fenton's reagent for treating oily wastewater and the efficacy of some experimental factors such as $\mathrm{pH}$ and temperature, initial concentrations of $\mathrm{TiO}_{2}, \mathrm{Fe}^{2+}$ and $\mathrm{H}_{2} \mathrm{O}_{2}$ on the oily wastewater treatment process.

The term photocatalysis was introduced in the 1930s. It is still a subject to a lot of researches. Photocatalysis is a special case of heterogeneous catalysis triggered by the irradiation of semiconductor materials with photons of energy adapted to the solid, and photocatalysts generate the formation of reagents, capable of decomposing by oxidation-reduction of organic or inorganic substances (Matthews et al. 1991).

The idea of photocatalysis method is centered about the excitation of a semiconductor (usually, titanium dioxide, $\mathrm{TiO}_{2}$ ) by light (UV or visible). Under the action of photons, the semiconductor (or catalyst) produces highly oxidizing free radicals allowing the destruction of compounds adsorbed on its surface (Mukherji et al. 2011; Fujishima and Honda 1970).

The semiconductor $\mathrm{TiO}_{2}$ converts photon energy into chemical energy by oxidation-reduction reaction. This causes the activation sites of $\mathrm{TiO}_{2}$ and molecular degradation of the compounds present (Herrmann et al. 1999). The degradation process then consists in a succession of radical oxidations initiated by strong oxidants such as $\mathrm{OH}$.

The $\mathrm{OH}^{\prime}$ is directly generated by the photolysis of water molecules adsorbed on the active sites of $\mathrm{TiO}_{2}$ (Fenton 1894).

Organic pollutants adsorbed on the catalyst are then degraded by successive radical reactions in non-toxic mineral species. The degradation capacity of the semiconductor is related to several parameters:

- the nature and intensity of light irradiation source or incident number photons for $\mathrm{TiO}_{2}$ activation of and the nature of the reaction medium is the amount of $\mathrm{TiO}_{2}$ (or active sites) for the production of hydroxyl (Kozlova et al. 2004) inside the water.

- Nature and concentrations of pollutants.

The following diagram (Fig. 3) summarizes all the physical and chemical processes that create the photocatalytic phenomenon.

The Fenton's reagent also is one the important AOPs methods which has been efficiently used as a chemical process for wastewater treatment and pre-treatment (Fenton 1894). The Fenton's system consists of ferrous salts combined with hydrogen peroxide under acidic conditions.

This reaction allows the generation of hydroxyl radicals as shown in the following reaction

$\mathrm{Fe}^{2+}+\mathrm{H}_{2} \mathrm{O}_{2} \rightarrow \mathrm{Fe}^{3+}+\mathrm{OH}^{-}+\mathrm{OH}^{-}$

$\mathrm{Fe}^{3+}$ produced can react with $\mathrm{H}_{2} \mathrm{O}_{2}$ and hydroperoxyl radical in the so-called Fenton-like reaction, which leads to regenerating $\mathrm{Fe}^{2+}$ (reactions 2, 3). $\mathrm{Fe}^{2+}$ regeneration is also possible by reacting with organic radical intermediates (reaction 4) given by Perez et al. (2002) as follows:

$$
\begin{aligned}
& \mathrm{Fe}^{3+}+\mathrm{H}_{2} \mathrm{O}_{2} \rightarrow \mathrm{Fe}^{2+}+\mathrm{HO}_{2}+\mathrm{H}^{+} \\
& \mathrm{Fe}^{3+}+\mathrm{HO}_{2} \rightarrow \mathrm{Fe}^{2+}+\mathrm{H}^{+}+\mathrm{O}_{2} \\
& \mathrm{Fe}^{3+}+\mathrm{R}^{\cdot} \rightarrow \mathrm{Fe}^{2+}+\mathrm{R}^{+}
\end{aligned}
$$

\section{Materials and methods}

\section{Wastewater characterization}

To study the effect of degradation on the efficiency of processes used on the oily waters, we took our sample from

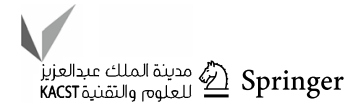


Fig. 3 Physical and chemical processes of the photocatalytic phenomenon

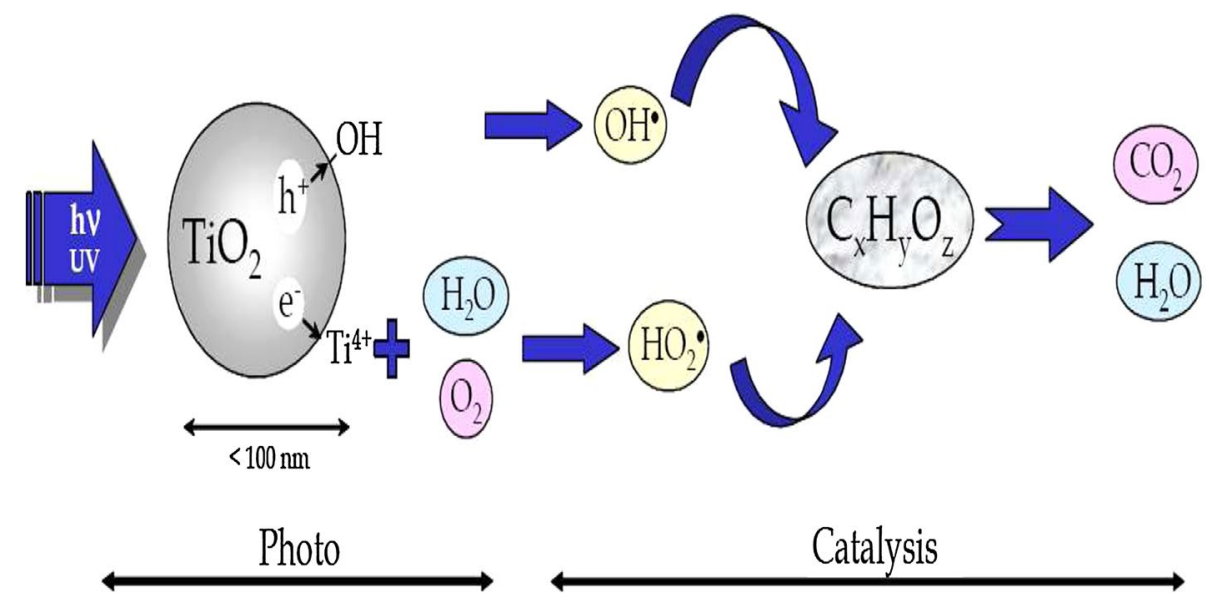

Haoud Berkaoui inlet station. The main properties of the oily wastewater are COD of $1298 \mathrm{mg} / \mathrm{l}$, turbidity of $120 \mathrm{NTU}, \mathrm{pH}$ 6.3 , and suspended solids of $435 \mathrm{mg} / \mathrm{l}$.

Samples are taken under strict aseptic conditions to avoid accidental contamination during handling. Sampling was carried out as follows:

The samples are taken using a sampling rod rinsed with the water to be taken.

Glass bottles and jerry cans designed for water sampling are pre-washed, rinsed thoroughly to remove any traces of detergent.

Preservation

- Completely filled vials are tightly closed and then covered with aluminum foil to provide double protection against possible contamination.

- The filled vials are kept in a refrigerator at low temperature $\left(5-10{ }^{\circ} \mathrm{C}\right)$.

This water will then be tested by the advanced oxidation method proposed for the degradation of oil and organic material in water and analyzed by spectroscopic method to determine the chemical oxygen demand (COD) in the water.

\section{Experimental materials}

The basic catalyst that we used while combining Fenton's reagent with heterogeneous photocatalytic handling is the titanium dioxide.
Powder of $\mathrm{TiO}_{2}$, of crystalline structure anatase $>99 \%$, has size between 5 and $10 \mathrm{~nm}$, with a specific surface SBET of approximately $320 \mathrm{~m}^{2} \mathrm{~g}^{-1}$.

$\mathrm{Fe}^{2+}$ in Fenton's reagent $\left(\mathrm{Fe}^{2+} / \mathrm{H}_{2} \mathrm{O}_{2}\right)$ is prepared by making a solution from $\mathrm{Fe}^{2+}$ salt. $\mathrm{H}_{2} \mathrm{O}_{2}$ was obtained in liquid ( $30 \%$ of $\mathrm{H}_{2} \mathrm{O}_{2}$ ) from a commercial supplier. Sulfuric acid is used for adjusting the $\mathrm{pH}$ of the oily wastewater samples during treatment. Properties of chemicals used in this work are presented in Table 1.

\section{Methodology}

All photochemical experiments were carried out in a batchmode laboratory-scale unit using a 500-ml beaker. First, the $\mathrm{pH}$ value of the oily wastewater samples was adjusted at the desired values with sulfuric acid or sodium hydroxide before being tested with the oxidation, and then, ferrous ions solution and hydrogen peroxide were added to produce hydroxyl radicals. Therefore, the combination was agitated by magnetic stirring and exposed to UV radiation $(254 \mathrm{~nm}$ wavelength), as demonstrated in Fig. 4. Samples were taken every $30 \mathrm{~min}$ in the discontinuous experiments for COD measurements.

\section{Irradiation system}

The primary radiation range of the UV lamp used in this work is $365 \mathrm{~nm}$, which corresponds to energy of about $3.4 \mathrm{eV}$. This energy is greater than the width of the forbidden band of $\mathrm{TiO}_{2}$
Table 1 Properties of chemicals used in the study

\begin{tabular}{lllll}
\hline Compound & Molecular weight & Formula & Manufacturer & Purity \\
\hline Iron chloride tetrahydrate & 198.8 & $\mathrm{FeCl}_{2}-4 \mathrm{H}_{2} \mathrm{O}$ & Sigma-Aldrich & $98.0 \%$ \\
Hydrogen peroxide & 134.01 & $\mathrm{H}_{2} \mathrm{O}_{2}$ & Sigma-Aldrich & 30 wt $\%$ \\
Sulfuric acid & 98.08 & $\mathrm{H}_{2} \mathrm{SO}_{4}$ & Sigma-Aldrich & $97.0 \%$ \\
Sodium hydroxide & 39.997 & $\mathrm{NaOH}$ & Sigma-Aldrich & $73 \%$ \\
\hline
\end{tabular}


Fig. 4 Schematic diagram of a laboratory-scale (photocatalysis-Fenton's reagent) test

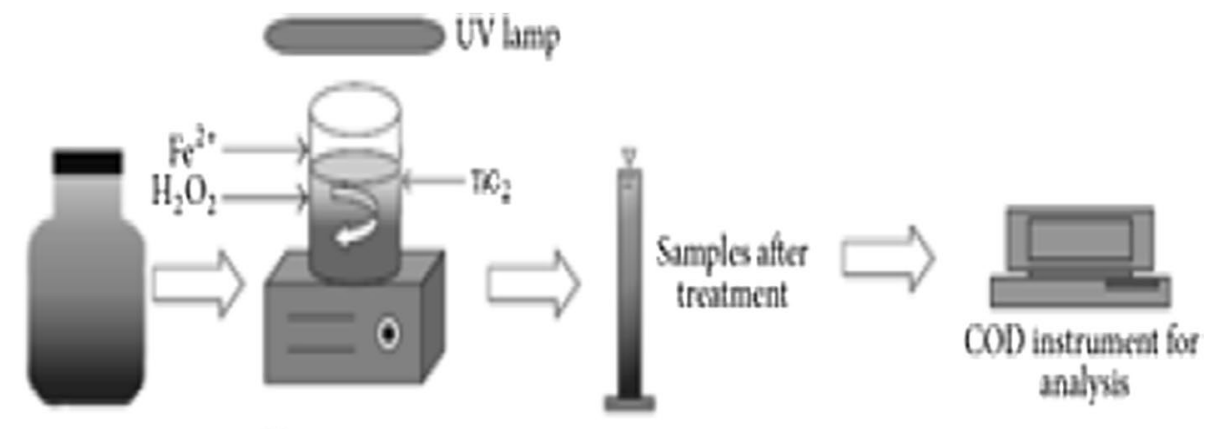

oby wastewate Magnetic stifnet
$(3.2 \mathrm{eV})$. So it will activate the material by generation of electrons and holes.

\section{Analytical determinations}

The oil concentration is one of the important parameters of oily wastewater treatment. This concentration of oil is reported in the form of $\mathrm{mg} / \mathrm{l}$. There are several methods to detect the presence of oil in the waste water and also to measure the amount of this oil such as COD measurement, measurement of turbidity, and total organic carbon (TOC) measurement (Portela et al. 2001; Rachu 2005).

The appropriate method is determined based on several parameters: the range of the existing quantity of oil, the response time of the measurement, the desired accuracy and the cost. However, for the specific application of measuring the pollution rate of oily wastewater, the choices are limited.

COD is used as a measure of pollutants. It is normally measured in industrial wastewater treatment plants and gives an indication of the effectiveness of the treatment process. It is generally expressed in terms of COD removal, measured as a percentage of the purified organic material during processing.

The COD measurements were done with the use of $\mathrm{HACH}$ analyzer (model HACH DR-2400). Turbidity was measured using a HACH $2100 \mathrm{~N}$ IS Turbidity meter (ISO method 7027). The $\mathrm{pH}$ of the wastewater was adjusted using a digital pH-meter (model PHM62 Radiometer). The oil removal rate $(\operatorname{Re} \%)$ is expressed by equation (Portela et al. 2001; Wanichkul et al. 2000):

$\operatorname{Re} \%=\frac{y_{0}-y}{y_{0}} \times 100$,

where $y_{0}$ and $y$ are the COD of the emulsion of the initial state and the final state, respectively.

\section{Results and discussion}

The studied experiments presented the results of the influence of experimental factors on coupling system (photocatalysis-Fenton's reagent) of oil degradation. The results were as follows:

\section{$\mathrm{TiO}_{2}$ concentration}

The results show positive influence of $\mathrm{TiO}_{2}$ concentration increase on the degradation rate, due to the increase in the number of oil molecules that were absorbed by the $\mathrm{TiO}_{2}$. The optimum $\mathrm{TiO}_{2}$ dosage in combined system (photocatalysis-Fenton's reagent) achieved was $0.8 \mathrm{~g} / \mathrm{l} . \mathrm{TiO}_{2}$ dosage greater than the maximum value $(0.8-1 \mathrm{~g} / \mathrm{l})$ has a negative effect on this process since the excess $\mathrm{TiO}_{2}$ particles increase the turbidity of the solution that will decrease the penetration of light into the solution, resulting in a reduction in production of hydroxyl radicals $(\mathrm{OH})$ at the $\mathrm{TiO}_{2}$ surface available to degrade the organic compounds in the oily water. These explanations were also mentioned by several studies (Fujishima and Honda 1970; Saien and Nejati 2007; Lee et al. 2003; Bauer et al. 1999).

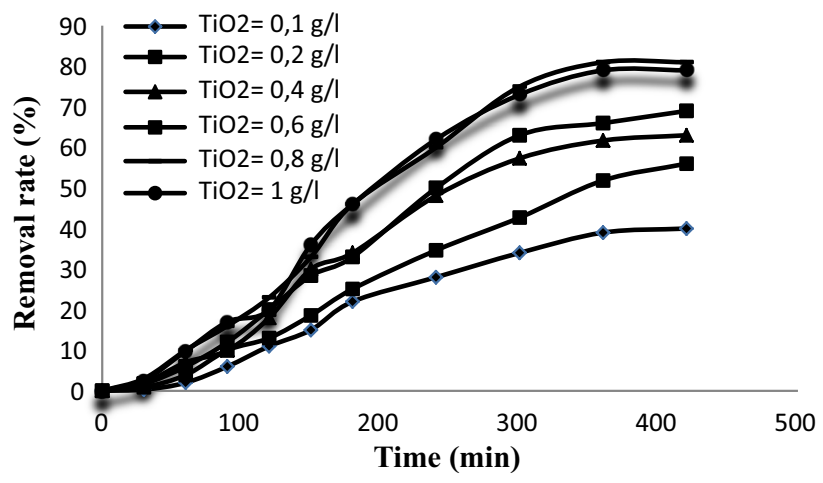

Fig. 5 Influence of $\mathrm{TiO}_{2}$ concentration on the (photocatalysis-Fenton's reagent) system (working conditions: $\mathrm{pH} 6.3 ; \mathrm{H}_{2} \mathrm{O}_{2}=400 \mathrm{mg} / \mathrm{l}$; $\left.\mathrm{Fe}^{2+}=40 \mathrm{mg} / \mathrm{l}\right)$

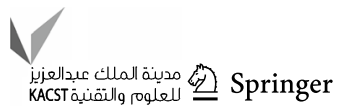


The relation between the oil removal rate $(\mathrm{Re} \%)$ and $\mathrm{TiO}_{2}$ concentration is shown in Fig. 5.

\section{Fenton's reagent concentration}

\section{$\mathrm{H}_{2} \mathrm{O}_{2}$ concentration}

Figure 6 shows the impact of the increase in $\mathrm{H}_{2} \mathrm{O}_{2}$ on degradation rate of the pollutant with the use of $\mathrm{TiO}_{2}$. The oil removal rate $\left(\mathrm{Re} \%\right.$ ) goes up with the increase in $\mathrm{H}_{2} \mathrm{O}_{2}$ concentration, However, the excess amount of hydrogen peroxide can cause the auto-decomposition of $\mathrm{H}_{2} \mathrm{O}_{2}$ into oxygen and water, decreasing the hydroxyl radicals production level. Therefore, decreasing the concentration of hydroxyl radicals and reagents reduces efficiency (Mukherji et al. 2011; Moraes et al. 2004; Tony et al. 2009). Based on that, the optimum $\mathrm{H}_{2} \mathrm{O}_{2}$ concentration in combined system (photocatalysis-Fenton's reagent) is between 400 and $600 \mathrm{mg} / \mathrm{L}$.

\section{Iron concentration}

Similar to the previous experimental factors $\left(\mathrm{TiO}_{2}, \mathrm{Fe}^{2+}\right)$, the oil removal rate $(\mathrm{Re} \%)$ increases with increasing iron concentration in the solution. The optimal concentration of iron observed was between 40 to $60 \mathrm{mg} / \mathrm{l}$ and going beyond that value adversely affects the process as shown in Fig. 7. This could be explained by:

- The addition of ferrous ions increases the turbidity of the wastewater during phototreatment, which prevents the absorption of the UV light necessary for the photoFenton process.

- The excess of ferrous ions may react with a compound that produces an $\mathrm{OH}^{-}$radical that inhibits the reaction rate (Neyens et al. 2003).

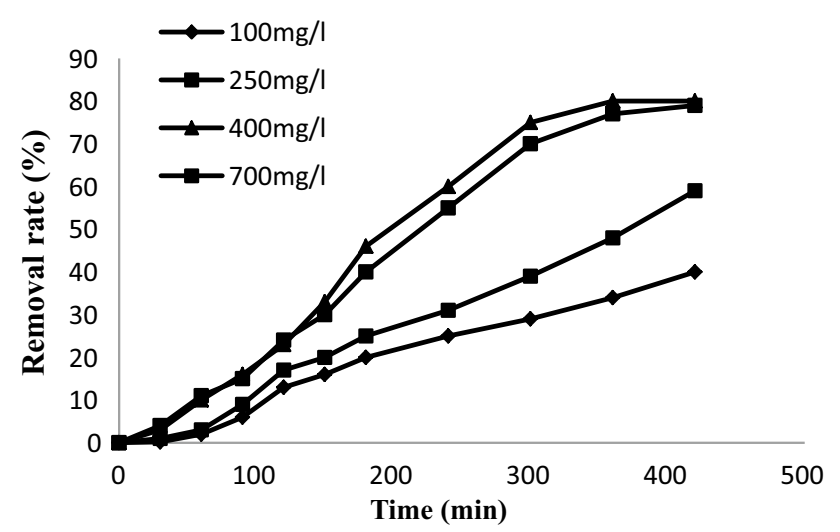

Fig. 6 Influence of $\mathrm{H}_{2} \mathrm{O}_{2}$ concentration on the (photocatalysis-Fenton's reagent) system (working conditions: $\mathrm{pH}$ 6.3; $\mathrm{TiO}_{2}=0.8 \mathrm{~g} / \mathrm{l}$; $\left.\mathrm{Fe}^{2+}=40 \mathrm{mg} / \mathrm{l}\right)$

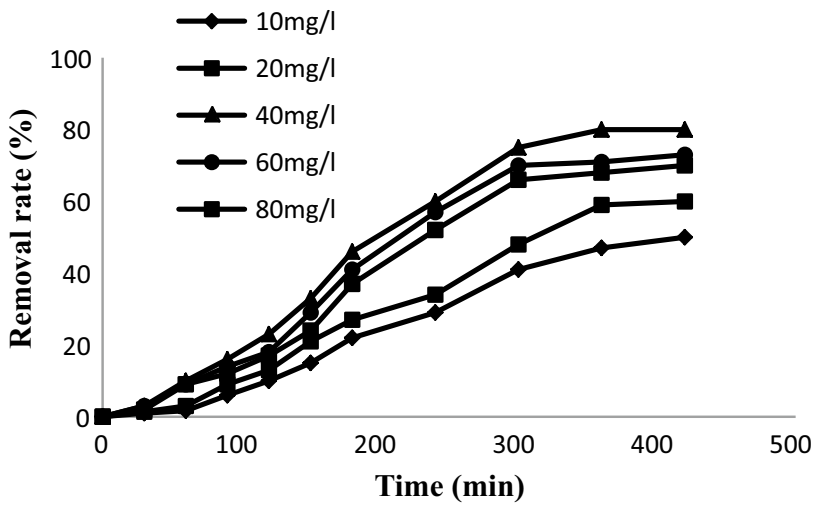

Fig. 7 Influence of $\mathrm{Fe}^{2+}$ concentration on the (photocatalysis-Fenton's reagent) system (working conditions: $\mathrm{pH}$ 6.3; $\mathrm{TiO}_{2}=0.8 \mathrm{~g} / \mathrm{l}$; $\left.\mathrm{H}_{2} \mathrm{O}_{2}=400 \mathrm{mg} / \mathrm{l}\right)$

\section{pH}

The $\mathrm{pH}$ value is an important parameter for AOPs process especially for photocatalytic and Fenton's reagent catalysts degradation of charged organic pollutants, because the $\mathrm{pH}$ value of solution will change the existed configuration of degraded species and surface charges of catalysts.

To investigate the influence of the initial $\mathrm{pH}$ on oil photodegradation, oily water solutions are prepared and the initial $\mathrm{pH}$ are adjusted either with an $\mathrm{H}_{2} \mathrm{SO}_{4}$ solution or with a $\mathrm{NaOH}$ solution according to the desired $\mathrm{pH}$. These mixtures are irradiated under the same experimental conditions as without $\mathrm{pH}$ adjustment. The results obtained are given in Fig. 8.

The shape of the curves is identical according to the pH. From Fig. 8, it can be stated that the performance of the photocatalytic degradation of the pollutant is strongly related to the initial $\mathrm{pH}$ of the sample to be irradiated. The

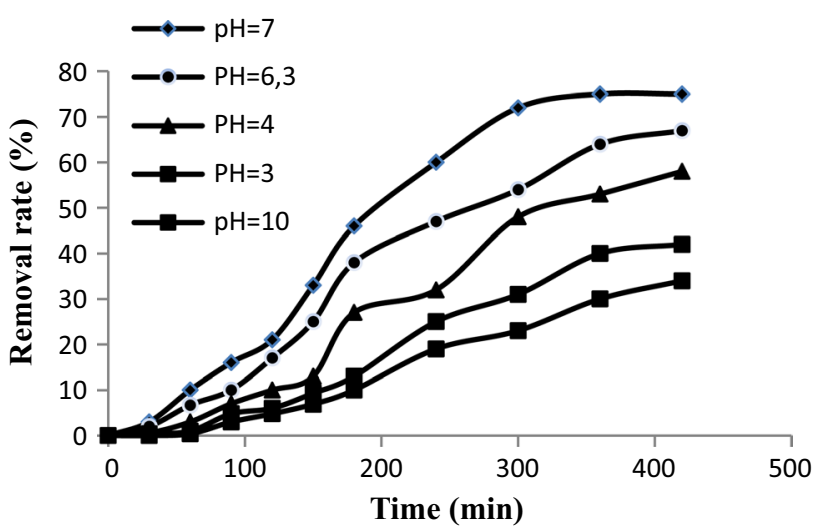

Fig. 8 Influence of $\mathrm{pH}$ on the (photocatalysis-Fenton's reagent) system (working conditions $\mathrm{TiO}_{2}=0.8 \mathrm{~g} / \mathrm{l} ; \mathrm{H}_{2} \mathrm{O}_{2}=400 \mathrm{mg}$; $\left.\mathrm{Fe}^{2+}=40 \mathrm{mg} / \mathrm{l}\right)$ 
best oil degradation efficiencies were obtained at the initial $\mathrm{pH}$ values between 6 and 7. On the other hand, very acidic or very basic solutions delay the photocatalytic process of the pollutant. This could be due to the fact that the oil is a nonionic compound and that the better efficiency would be obtained at the PZC pH of the catalysts which, moreover, is close enough to the natural $\mathrm{pH}$ (6.8) (Mustafa 2014) of the irradiated oil solution.

\section{Initial concentration of the pollutant (oil)}

From a real sample of oily water, synthetic samples were prepared to vary the initial concentration, actual sample mixture diluted with distilled water.

The first sample was diluted for $50 \%$ and COD value found was $700 \mathrm{mg} / \mathrm{l}$; the second sample was diluted for $25 \%$ and COD value found was $300 \mathrm{mg} / \mathrm{l}$. The two samples were compared with the original sample ( $100 \%$ concentration)

We performed the test with $\mathrm{H}_{2} \mathrm{O}_{2}=400 \mathrm{mg} / \mathrm{l}$, $\mathrm{Fe}^{+2}=40 \mathrm{mg} / \mathrm{l}, \mathrm{TiO}_{2}=0.8 \mathrm{~g} / \mathrm{l}$, and $\mathrm{pH}(6.3)$ in different sample concentrations 300,700 , and $1298 \mathrm{mg}-\mathrm{COD} / \mathrm{l}$, under the following conditions: stirring and artificial UV. The results of the evolution of the COD are given in Fig. 9:

This experiment has proven that the degradation rate is increased after diluting the initial emulsion concentration, and it also shows that the oil removal rates (Re\%) are 79, 88, and $98 \%$ for the COD of 1298,700 , and $300 \mathrm{mg} / \mathrm{l}$, respectively. This could be attributed to the decrease in turbidity of the oily wastewater. The emulsion turbidity for an initial COD of $1298 \mathrm{mg} / \mathrm{l}$ was 120 NTU. However, it gave only 25 NTU when the initial COD was $300 \mathrm{mg} / \mathrm{l}$.

Decreasing turbidity clearly helps in the penetration of the UV light, what leads to the oil removal rate improvement. This result is consistent with the findings reported by Najjar et al. (2001).

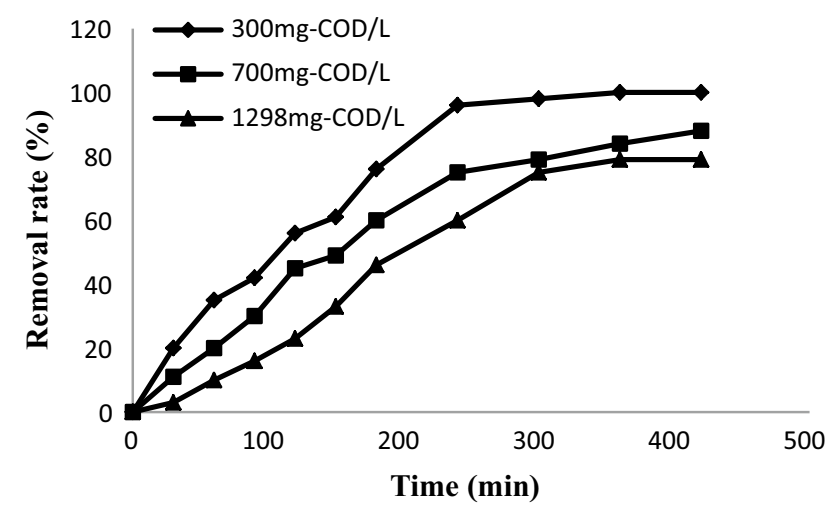

Fig. 9 Influence of initial pollutant concentration on oil degradation by (photocatalysis-Fenton's reagent) system at working conditions: $\mathrm{H}_{2} \mathrm{O}_{2}=400 \mathrm{mg} / \mathrm{l}, \mathrm{Fe}^{+2}=40 \mathrm{mg} / \mathrm{l}, \mathrm{pH}=6.3$ and $\mathrm{TiO}_{2}=0.8 \mathrm{~g} / \mathrm{l}$

\section{Temperature}

In general, it is agreed that the increase in temperature increases the number of collisions between molecules and therefore results in an improvement in oxidation rate $(\mathrm{Wu}$ et al. 2010; Guedes et al. 2003).

Figure 10 gives the influence of changing temperature on the treatment efficiency. The higher degradation of oily wastewater Re\% (up to $85 \%$ ) was observed in $50{ }^{\circ} \mathrm{C}$.

However, this value cannot be considered as an optimal temperature according to some literature reports (Guedes et al. 2003; Kavitha and Palanivelu 2005; Lucas and Peres 2009). Those experiments have reported the optimal temperature from 30 to $50{ }^{\circ} \mathrm{C}$. Therefore, going over that range had some opposite effects on the degradation rate due to selfaccelerating decomposition of hydrogen peroxide when the temperature approaches $60{ }^{\circ} \mathrm{C}$ causing decrease in the production rate of $\mathrm{OH}$ which can disturb the treatment process.

\section{Conclusion}

In this work, we studied the efficiency of combining two treatment methods (photocatalysis-Fenton's reagent) with an ultraviolet light source for oily wastewater treatment. This technique is based on the generation of hydroxyl radicals and represents a very promising alternative as oily organic pollutants are toxic substances on which conventional treatment processes sometimes have no effect.

We were able to reach the optimal experimental conditions to remove pollutants by investigating the influence of different experimental factors on the oil removal, including $\mathrm{pH}$, initial concentration for each of the $\mathrm{TiO}_{2}, \mathrm{H}_{2} \mathrm{O}_{2}$,

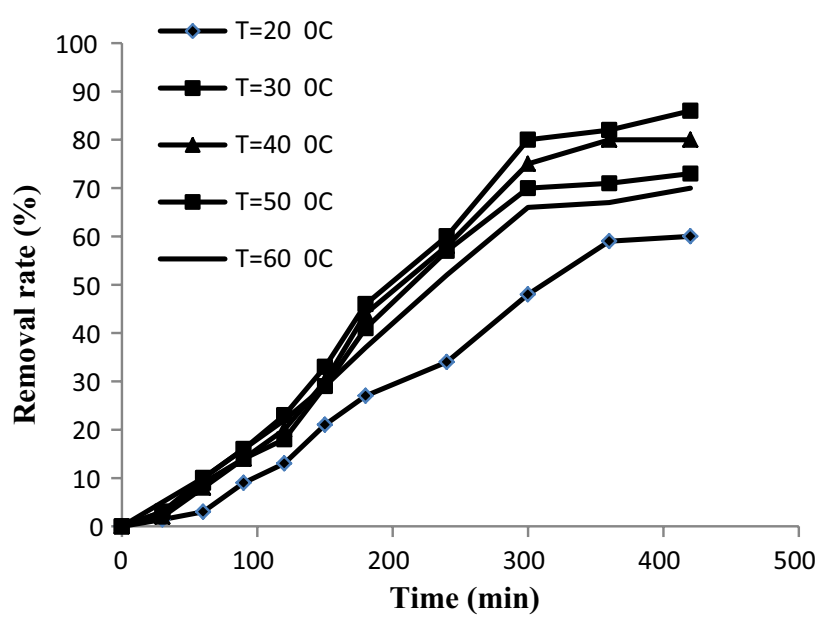

Fig. 10 Influence of temperature on oil degradation by (photocatalysis-Fenton's reagent) system at working conditions: $\mathrm{H}_{2} \mathrm{O}_{2}=400 \mathrm{mg} / \mathrm{L}, \mathrm{Fe}^{+2}=40 \mathrm{mg} / \mathrm{L}, \mathrm{pH}=6.3$ and $\mathrm{TiO}_{2}=0.8 \mathrm{~g} / \mathrm{L}$

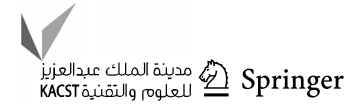


$\mathrm{Fe}^{2+}$, oil pollutants, and temperature. The results were as follows:

- The optimal amount of catalyst $\left(\mathrm{TiO}_{2}\right)$ is generally a function of the surface and the irradiated volume of the reactor. Photocatalysis is more of a surface phenomenon than a mass quantity of catalyst to be irradiated. The realization of a reactor to treat large volumes of water would therefore increase the amount exposed to the light of this reactor. The best elimination rate obtained for $\mathrm{T} \mathrm{TiO}_{2}$ concentration equals to $0.8 \mathrm{~g} / \mathrm{l}$ corresponding to a removal rate of $80 \%$ of the COD.

- As for Fenton's reagent, the optimal dose of $\mathrm{Fe}^{+2}$ and $\mathrm{H}_{2} \mathrm{O}_{2}$ is approximately $40 \mathrm{mg} / \mathrm{l}$ and $400 \mathrm{mg} / \mathrm{l}$, respectively. The increase above these concentrations has a negative effect on the degradation process which means a decrease in the efficiency of COD removal.

- The initial oil concentration of the oily water solution has shown a good influence in the process for low values, and it turns out that exceeding $25 \%$ of oily water concentration negatively affects the process; the best removal of COD recorded was $98 \%$.

- The optimum temperature is found for (photocatalysisFenton's reagent) degradation of oily wastewater. The highest degradation reached $(83 \%)$ was at $45^{\circ} \mathrm{C}$ and over than this degree, the results were unsatisfactory, because hydrogen peroxide undergoes self-accelerating decomposition at higher temperature.

- Regarding $\mathrm{pH}$ value, best recorded results (80\%) were between 6 and 7, and also the results showed that the very acidic $(\mathrm{pH}=2)$ or very basic solution $(\mathrm{pH}=10)$ has a negative effect on the degradation process.

The overall results of this study (heterogeneous photocatalysis treatment coupled with Fenton's reagent) summarize that the application of the photocatalytic process is a feasible method for treating oily wastewater, which allows a significant reduction in COD.

Nowadays, the study demonstrates an economical and effective strategy for removing both a large portion of oily organic pollutants and oils that generally coexist in industrial wastewater as an alternative to several successive treatment processes.

One of the disadvantages of this system is the use of artificial light which can increase the processing cost because of the average life of the lamp and the consumption of electrical energy. In this context, the use of sunlight would significantly reduce the cost of treatment, thus providing an important step toward industrial applications. Generally speaking, this process can be qualified as a cleanup process and it is a part of a sustainable development perspective and its operation is based on renewable energy.
Acknowledgements The authors of this paper are very thankful to for colleagues from the Department and Laboratory of Process Engineering (GP)/Kasdi Merbah University, Ouargla, Algeria, and Laboratory of the Corrosion Treatment Service, as well as on the sewage treatment plant, within the Regional Directorate Haoud Berkaoui for their remarkable contribution to the studies of these interesting water/oily wastewater treatment processes and are grateful to all of those who have helped us in this work.

Open Access This article is distributed under the terms of the Creative Commons Attribution 4.0 International License (http://creativeco mmons.org/licenses/by/4.0/), which permits unrestricted use, distribution, and reproduction in any medium, provided you give appropriate credit to the original author(s) and the source, provide a link to the Creative Commons license, and indicate if changes were made.

\section{References}

Andreozzi R, Caprio V, Insola A, Marott R (1999) Advanced oxidation processes (AOP) for water purification and recovery. Catal Today 53:51-59

Arslan AI, Teksoy S (2007) Acid dyebath effluent pretreatment using Fenton's reagent: process optimization, reaction kinetics and effects on acute toxicity. Dyes Pigments 73:31-39

Bauer R, Fallmann H (1997) The photo-Fenton oxidation-a cheap and efficient waste water treatment method. Res Chem Intermed 23(4):341-354

Bauer R, Waldner G, Fallmann H, Hager S, Klare M, Krutzler T, Malato S, Maletzky P (1999) The photo-Fenton reaction and the $\mathrm{TiO}_{2} / \mathrm{UV}$ process for waste water treatment-novel developments. Catal Today 53:131-144

Bautista P, Mohedano AF, Gilarranz MA (2007) Application of Fenton oxidation to cosmetic wastewaters treatment. J Hazard Mater 143:128-134

Beltrán FJ, González M, Rivas FJ, Alvarez P (1998) Fenton reagent advanced oxidation of polynuclear aromatic hydrocarbons in water. Water Air Soil Pollut 105:685-700

Beltrán-Heredia J, Torregrosa J, García J, Domínguez JR, Tierno JC (2001) Degradation of olive mill wastewater by the combination of Fenton's reagent and ozonation processes with an aerobic biological treatment. Water Sci Technol 44:103-108

Carriazo J, Guélou E, Barrault J, Tatiboue JM, Molina R, Moreno $S$ (2005) Catalytic wet peroxide oxidation of phenol by pillared clays containing Al-Ce-Fe. Water Res 39:3891-3899

Chen S, Sun D, Chung JS (2007) Treatment of pesticide wastewater by moving-bed biofilm reactor combined with Fenton-coagulation pre-treatment. J Hazard Mater 144:577-784

Fenton HJH (1894) Oxidation of tartaric acid in presence of iron. J Chem Soc 65:899-910

Flotron V (2004) La réaction de Fenton comme procédé de réhabilitation dans le traitement des eaux: application à la dégradation des hydrocarbures aromatiques polycycliques dans les eaux et les boues résiduaires. National Agronomic Institute, Paris Grignon, Graduate School Abies, Paris

Fujishima A, Honda K (1970) Electrochemical photolysis of water at a semiconductor electrode. Nature 238(5358):37-38

Gao Y, Yang M, Hu J, Zhang Y (2004) Fenton's process for simultaneous removal of TOC and $\mathrm{Fe}^{2+}$ from acidic waste liquor. Desalination 160:123-130

Glaze WH, Kwang JW, Chapin DH (1987) Chemistry of water treatment processes involving ozone, hydrogen peroxide and ultraviolet radiation. Ozone Sci Eng 9:335-352 
Guedes AMFM, Madeira LMP, Boaventura RAR, Costa CAV (2003) Fenton oxidation of cork cooking wastewater-overall kinetic analysis. Water Res 37(13):3061-3069

Guillard C, Disdier J, Monnet C, Dussaud J, Malato S, Blanco J, Maldonado MI, Herrmann J-M (2003) Solar efficiency of a new deposited titania photocatalyst: chlorophenol, pesticide and dye removal applications. Appl Catal B Environ 46:319

Gulkaya I, Surucu GA, Dilek FB (2006) Importance of $\mathrm{H}_{2} \mathrm{O}_{2} / \mathrm{Fe}^{2+}$ ration in Fenton's treatment of a carpet dyeing wastewater. J Hazard Mater B 136:763-769

Herrmann JM, Guillard C, Disdier J (1999) Heterogeneous photocatalysis: fundamentals and applications to the removal of various types of aqueous pollutants. Catal Today 53:115-129

Hermann JM, Guillard C, Disdier J (2000) Photocatalytic degradation of pesticides in agricultural used waters. C R Acad Sci Ser IIC Chem 3:417-422

Huchon R (2006) Activité photocatalytique de catalyseurs déposés sur différents supports «médias » : application à la conception d'un photoréacteur pilote. Ph.D. thesis, University of Lyon I

Ioan I, Wilson S, Lundanes E, Neculai A (2007) Comparison of Fenton and sono-Fenton bisphenol A degradation. J Hazard Mater 142:559-563

Kavitha V, Palanivelu K (2005) Destruction of cresols by Fenton oxidation process. Water Res 39(13):3062-3072

Klavarioti M, Mantzavinos D, Kassinos D (2009) Removal of residual pharmaceuticals from aqueous systems by advanced oxidation processes. Environ Int 35:402

Kozlova EA, Smirniotis PG, Vorontsov AV (2004) Comparative study on photocatalytic oxidation of four organophosphorus simulants of chemical warfare agents in aqueous suspension of titanium dioxide. J Photochem Photobiol A Chem 162(2-3):503-511

Lee HS, Hur T, Kim S, Kim JH, Lee HI (2003) Effects of pH and surface modification of $\mathrm{TiO}_{2}$ with $\mathrm{SiOx}$ on the photocatalytic degradation of a pyrimidine derivative. Catal Today 84:173-180

Liu R, Chiu HM, Shiau C-S, Yu-Li YR, Hung Y-T (2007) Degradation and sludge production of textile dyes by Fenton and photo-Fenton processes. Dyes Pigments 73:1-6

Lucas MS, Peres JA (2009) Removal of COD from olive mill wastewater by Fenton's reagent: kinetic study. J Hazard Mater 168(2-3):1253-1259

Martins AF, Vasconcelos TG, Wilde ML (2005) Influence of variables of the combined coagulation-Fenton-sedimentation process in the treatment of trifluraline effluent. J Hazard Mater B 127:111-119

Matthews R, Pelizzetti E, Schiavello M (eds) (1991) Photochemical conversion and storage of solar energy. Kluwer, Dortdrech

Moraes JEF, Quina FH, Nascimento CAO, Silva DN, Filho OC (2004) Treatment of saline wastewater contaminated with hydrocarbons by the photo-Fenton process. Environ Sci Technol 38:1183-1187

Mukherji A, Sun CH, Smith SC, Lu GQ, Wang LZ (2011) Photocatalytic hydrogen production from water using $\mathrm{N}$-doped $\mathrm{Ba}_{5} \mathrm{Ta}_{4} \mathrm{O}_{15}$ under solar irradiation. J Phys Chem C 115(31):15674-15678

Mustafa YA (2014) Heterogeneous photocatalytic degradation for treatment of oil from wastewater. Al-Khwarizmi Eng J 10(3):53-61

Najjar W, Chirchi L, Santosb E, Ghorhel A (2001) Kinetic study of 2-nitrophenol photodegradation on Al-pillared montmorillonite doped with copper. J Environ Monit 3:697-701

Neyens E, Baeyens J, Weemaes M, Deheyder B (2003) Pilot-scale peroxidation $\left(\mathrm{H}_{2} \mathrm{O}_{2}\right)$ of sewage sludge. J Hazard Mater B 98:91-106
Perez M, Torrades F, Garcia-Hortal JA, Domenech X, Peral J (2002) Removal of organic contaminants in paper pulp treatment effluents under Fenton and photo-Fenton conditions. Appl Catal B 36(1):63-74

Portela JR, Lopez J, Nebot E, Martinez de la Ossa E (2001) Elimination of cutting oil wastes by promoted hydrothermal oxidation. $\mathrm{J}$ Hazard Mater B 88:95-106

Rachu S (2005) Contribution a la mise au point d'un logiciel de calcul de procèdes et filières de traitement d'eaux résiduaires huileuses. Ph.D. thesis, I.N.S.A. Toulouse

Rivas FJ, Beltrán FJ, Gimeno O, Frades J (2001) Treatment of olive oil mill wastewater by Fenton's reagent. J Agric Food Chem 49:1873-1880

Rivas FJ, Beltrán FJ, Gimeno O, Alvarez P (2003) Optimisation of Fenton's reagent usage as a pre-treatment for fermentation brines. J Hazard Mater 96:277-290

Rivas FJ, Beltrán F, Carvalho F, Acedo B, Gimeno O (2004) Stabilized leachates: sequential coagulation-flocculation + chemical oxidation process. J Hazard Mater 116:95-102

Saien J, Nejati H (2007) Enhanced photocatalytic degradation of pollutants in petroleum refinery wastewater under mild condition. $\mathrm{J}$ Hazard Mater 148:491-495

San Sebastián Martínez N, Fíguls Fernández J, Font Segura X, Sánchez Ferrer A (2003) Pre-oxidation of an extremely polluted industrial wastewater by the Fenton's reagent. J Hazard Mater B 101:315-322

Sun H, Bai Y, Liu H, Jin W, Xu N (2009) Photocatalytic decomposition of 4-chlorophenol over an efficient $\mathrm{N}$-doped $\mathrm{TiO}_{2}$ under sunlight irradiation. J Photochem Photobiol A Chem 20(1):15-22

Tony MA, Zhao YQ, Purcell PJ, El-Sherbiny MF (2009) Evaluating the photo-catalytic application of Fenton's reagent augmented with $\mathrm{TiO}_{2}$ and $\mathrm{ZnO}$ for the mineralization of an oil water emulsion. J Environ Sci Health, Part A 44(5):488-493

Umar M, Abdul Aziz H, Yusoff MS (2010) Trends in the use of Fenton, electro-Fenton and photo-Fenton for the treatment of landfill leachate. Waste Manag 30:2113

Wang S (2008) A comparative study of Fenton and Fenton like reaction kinetics in decolourisation of wastewater. Dyes Pigments 76:714-720

Wang N, Li X, Mele G, Wang Y, Quan X, Chen G (2009) Evaluation of bias potential enhanced photocatalytic degradation of 4-chlorophenol with $\mathrm{TiO}_{2}$ nanotube fabricated by anodic oxidation method. Chem Eng J 146:30-35

Wanichkul B, Ionescu E, Joye AL, Julien E, Aurelle Y (2000) Comparison of ultrafiltration and distillation processes for the treatment of cutting oil emulsion. In World filtration congress, UK, vol 8, pp 3-7

Wu Y, Zhou S, Qin F, Zheng K, Ye X (2010) Modeling the oxidation kinetics of Fenton's process on the degradation of humic acid. J Hazard Mater 179(1-3):533-539

Publisher's Note Springer Nature remains neutral with regard to jurisdictional claims in published maps and institutional affiliations. 